Is Screening for Chlamydia and Gonorrhea in Men Who Have Sex With Men Associated With Reduction of the Prevalence of these Infections? A Systematic Review of Observational Studies

Peer-reviewed author version

Tsoumanis, Achilleas; HENS, Niel \& Kenyon, Chris Richard (2018) Is Screening for Chlamydia and Gonorrhea in Men Who Have Sex With Men Associated With Reduction of the Prevalence of these Infections? A Systematic Review of Observational Studies. In: SEXUALLY TRANSMITTED DISEASES, 45(9), p. 615-622.

DOI: $10.1097 / O L Q .0000000000000824$

Handle: http://hdl.handle.net/1942/27700 


\section{Is screening for chlamydia and gonorrhea in men who have sex with men associated with reduction of the prevalence of these infections? A systematic review of observational studies}

\section{Achilleas Tsoumanis}

Clinical Trials Unit, Institute of Tropical Medicine, Antwerp, Belgium. Centre for Health Economic Research and Modeling Infectious Diseases, Vaccine and Infectious Disease Institute (VAXINFECTIO), University of Antwerp, Antwerp, Belgium

\section{Niel Hens, MMath, MSc Biostatistics, PhD}

Centre for Health Economic Research and Modeling Infectious Diseases, Vaccine and Infectious Disease Institute (VAXINFECTIO), and Epidemiology and Social Medicine (ESOC), University of Antwerp, Antwerp, Belgium. Center for Statistics, I-BioStat, UHasselt (Hasselt University), Hasselt, Belgium

\section{Chris Richard Kenyon, MBChB, MPH, BA, MA, FCP(SA), DTMH, CertID(SA), PhD}

Professor in Sexually Transmitted Infections HIV/STI Unit, Institute of Tropical Medicine, Antwerp, Belgium. Division of Infectious Diseases and HIV Medicine, University of Cape Town, Anzio Road, Observatory 7700, South Africa

\section{Summary}

This systematic review of uncontrolled observational studies was not able to provide evidence that screening for chlamydia and gonorrhea lowers the prevalence of these infections in MSM. 


\section{Abstract \\ Background:}

Neisseria gonorrhoeae (gonorrhea) could become untreatable in the near future. Indeed, while the treatment of symptomatic gonorrhea in core groups, such men who have sex with men (MSM), is crucial for gonorrhea control programs, screening for and treating asymptomatic gonorrhea/ Chlamydia trachomatis(chlamydia) in MSM may contribute to antibiotic resistance in gonorrhea. In this systematic review we aim to assess if there is evidence that screening MSM for gonorrhea/chlamydia is associated with a decline in the prevalence of these infections.

Methods:

We conducted a systematic review in PubMed and Web of Science for relevant studies including uncontrolled observational studies and reported the results following the PRISMA guidelines. The change in estimated prevalences for chlamydia and gonorrhea across the different time points for three anatomical sites (oral, urethral and anal) were collected and examined.

Results:

Twelve studies met our entry criteria. We were able to statistically assess the change in prevalence in 10 out of 12 studies. In three studies, there was a significant increase in chlamydia prevalence, while for gonorrhea two studies reported a significant increase and two others a decrease. Our review provides little evidence that screening for gonorrhea and chlamydia in MSM has an effect on the prevalence of these infections. No evidence was found that more frequent screening reduces prevalence more effectively than annual screening.

Conclusion:

Our study was not able to provide evidence that screening for chlamydia and gonorrhea lowers the prevalence of these infections in MSM. Randomized controlled trials are required to assess the risks and benefits of gonorrhea/chlamydia screening in high and low risk MSM. 


\section{Introduction}

Neisseria gonorrhoeae (gonorrhea) has developed resistance to all classes of antibiotics it has been exposed to including the current recommended combination therapy ${ }^{1-3}$ and there is a real concern that gonorrhea could become untreatable in the near future ${ }^{3-5}$. Resistance has typically first emerged in core-groups such as sex workers or men who have sex with men (MSM) with high rates of partner change ${ }^{6}$. One of the strategies proposed to deal with both the increasing prevalence of gonorrhea and the threat of resistance is frequent screening and early treatment of MSM ${ }^{6-9}$. Several guidelines from around the world recommend at least annual screening for gonorrhea and Chlamydia trachomatis (chlamydia) for sexually active MSM, and every 3-6 months in those at highest risk ${ }^{10-17}$ (see Table 1). Screening programs may reduce the incidence of asymptomatic gonorrhea/chlamydia, reduce HIV and gonorrhea/chlamydia spread ${ }^{18}$ and result in a reduced prevalence of these infections. Screening programs may however result in selection pressure for antibiotic resistance development ${ }^{6,19-21}$. Since screening programs typically detect gonorrhea in $5-12 \%$ of those screened ${ }^{22,23}$ and most gonorrhea infections in MSM are asymptomatic ${ }^{24-26}$, screening programs may place more drug selection pressure on gonorrhea than treatment of symptomatic gonorrhea ${ }^{27}$. This increased risk of antibiotic resistance may be considerable and could outweigh the combined benefits of screening. Pre-exposure prophylaxis (PrEP) programs, that utilize antiretrovirals to reduce the incidence of HIV, are being rolled out around the world. These programs typically recommend gonorrhea/chlamydia screening every 3 to 6 months and it is thus particularly prescient to establish that the benefits of screening outweigh the harms ${ }^{23,28,29}$. 
A previous systematic review conducted to inform the recently updated U.S. Preventive Services Task Force (USPSTF) guidelines for gonorrhea and chlamydia screening in men found no randomized controlled trials (RCTs) or controlled observational studies of the effect of screening on gonorrhea/chlamydia prevalence (period reviewed 1 January 2004 to 13 June 2014) ${ }^{30}$. As a result, the USPSTF reached a different conclusion to that of other guidelines (Table 1); that the current evidence is insufficient to assess the balance of benefits and harms of screening for gonorrhea/chlamydia in $\mathrm{MSM}^{30}$. To build on the results of the USPSTF review we conducted a systematic review that included uncontrolled observational studies to assess if there is evidence that screening for chlamydia and gonorrhea in MSM was associated with a reduction in the prevalence of these STIs.

\section{Methods}

\section{Search strategy}

We conducted a systematic review on literature published in PubMed and Web of Science between January $1^{\text {st }} 1990$ and June $15^{\text {th }} 2017$, and reported the results following the PRISMA guidelines ${ }^{31 s}$. The search terms used were "MSM" AND "screening" AND ("Chlamydia" OR "Gonorrhea") AND (“incidence" OR "prevalence”). A more detailed description of the search terms is presented in the supplementary material (Supplemental Digital Content (SDC) 1). All studies, including uncontrolled observational studies, evaluating the prevalence of gonorrhea or chlamydia in MSM at multiple time points were potentially eligible for inclusion. Additionally, the reference lists of those potential articles were manually screened for studies that met the criteria for inclusion. We also conducted a manual search for relevant data from studies that used PrEP in MSM cohorts published or presented in conferences. All included studies were independently reviewed by two reviewers (AT and CRK). PRISMA checklists are presented in supplementary material (SDC 2). 


\section{Study selection and quality assessment}

A publication was considered for inclusion if the study described was a randomized clinical trial or a cohort study, participants were screened for chlamydia and/or gonorrhea and data (number of participants tested and number of cases, prevalence or positivity rates) were presented for at least 2 time points within a period of 12 months. All candidate articles had to refer to an MSM study population to be included in the review. Studies were excluded if they did not have a relevant target population (MSM). All included studies were assessed for methodological quality and risk of bias using a customized version of the Quality Assessment Tool for Observational Cohort and Cross-Sectional Studies by the National Heart, Lung, and Blood Institute ${ }^{32 \mathrm{~s}}$.

\section{Data extraction and analysis}

Data were extracted independently from the published articles and online supplementary material. Prevalence among the MSM tested was calculated separately for chlamydia and gonorrhea and per anatomical screening site (pharynx, rectum and urethra) when possible by dividing the number of positive cases over the number of persons tested. For the papers that only provided aggregated data on infection (chlamydia + gonorrhea) or anatomical screening site, the prevalence for this combined outcome was calculated. In papers where data were only presented graphically, images were digitized into data points using R package digitize ${ }^{33 s}$. Confidence intervals were extracted when reported or calculated where possible and were included in the final dataset. The reviewed results are presented graphically with prevalence of infections across time and with forest plots for the change of prevalence between baseline and 6/12 months for each infection and anatomical site separately. Chi-square testing for trend in proportions was used to assess if chlamydia or gonorrhea prevalence changed during the screening period. All analyses and graphics were done using statistical software R (version 3.4.1) ${ }^{34 \mathrm{~s}}$. 


\section{Results}

A total of 293 articles were identified by searching PubMed and Web of Science databases (Figure 1).

After excluding 91 duplicate entries, we identified 202 unique references and screened 74 full text articles based on title and abstract. Five articles met the inclusion criteria ${ }^{25,35 s-38 s}$ and three additional papers were obtained through review of the reference list of the included articles ${ }^{39 s-41 s}$. Four articles and posters were included from publications and conference presentations of studies using PrEP on MSM ${ }^{22-24,26}$. The 12 included studies were published between 2000 and 2015. Three of the included studies were repeated cross-sectional surveys and seven were cohort studies, two of which were open cohorts, and three were PrEP demonstration studies that also collected STI data during patients' planned visits. The remaining two studies were randomized clinical trials; one for PrEP effectiveness and one for a behavioral intervention, both of which served as closed cohorts for our research question, since they reported STI testing data on multiple time points. All studies reported screening data for chlamydia and gonorrhea, either separately for the two infections and the different screening sites or combinations of them, except the study from Morris et al. (Explore study) ${ }^{24}$ that only screened for pharyngeal gonorrhea.

In 4 of the studies screening was performed annually (North London HIV cohort ${ }^{25}$, Ontario HIV cohort ${ }^{35 s}$, Washington cohort ${ }^{39 s}$, Melbourne cohort ${ }^{40 s}$ ) and in the other 8 studies more frequently (Table 2). The study of Debattista et al. (Brisbane night club study) ${ }^{36 s}$ only screened at two time points, 2 months apart. In 11 studies, screening included urethral testing, whereas 10 studies screened for pharyngeal infections and 9 for rectal infections. Only 8 studies screened at all three sites. The percentage of the study populations screened varied from 13 to $93 \%$ for the open population studies and the retention rate from 54 to $79 \%$ for the 
closed cohorts. The characteristics of each study are summarized in Table 2. One study only reported prevalence without providing number of persons tested at each time point (Ontario cohort), while another only reported prevalence in the form of a graph, which was digitized to access the data points (Explore). In both cases, the lack of total number of persons tested at each time point meant that we could not conduct statistical tests to assess trends in prevalence. Four of the studies were evaluated as being of good quality (low risk of bias), five as fair quality and three as poor quality (SDC 3).

\section{Change in prevalence of Chlamydia trachomatis}

In the three studies where there was a statistically significant change in prevalence (North London HIV cohort, Melbourne cohort and San Francisco PrEP study), the prevalence increased (Table 3; SDC5.1). In two of those studies the data came from aggregated prevalence over the three anatomical screening sites and in one (Melbourne cohort) from rectal chlamydial infection. The change of prevalence between baseline and 6 and 12 months is presented graphically using forest plots for every anatomical site. The change of prevalence regresses around the 0 axis for both time points (Figure $2 \mathrm{a}$ and $2 \mathrm{~b}$ ).

\section{Change in prevalence of Neisseria gonorrhoeae}

Gonorrhea prevalence increased in all three screening sites in the Melbourne cohort (p-value $<0.001$ in all sites) and in the rectum in the San Francisco PrEP study (p-value $<0.001$; Table 3; SDC5.2)). gonorrhea prevalence decreased in the rectum site in the Los Angeles HIV cohort $(\mathrm{p}$-value $=0.01)$ and in the urethra site in the iPREX study $(\mathrm{p}$-value $=0.01)$. Similarly to chlamydia, the change of gonorrhea prevalence between baseline and 6 and 12 months lies around the 0 axis. Also, as in chlamydia, the change in prevalence at 6 months seems more 
apparent for the majority of the studies compared to the 12-month time point (Figure 3a and $3 b)$.

\section{Change in prevalence of gonorrhea/chlamydia combined}

The changes of combined gonorrhea/chlamydia prevalence reported in the Demo PrEP study had a U-shape in the rectum, pharynx and urethra sites while in SPARK it had an inverse Ushape (Figure 4). There was no significant trend in the prevalence for either study. Both studies were community-based PrEP studies that screened with nucleic acid amplification tests at 3 monthly intervals for 12 months. The change in prevalence from those two studies between baseline and 6 and 12 months are presented in Figures $2 \mathrm{a}, \mathrm{b}$ and 3a,b (identical results for chlamydia and for gonorrhea).

\section{Risk of bias assessment}

Three studies had a high risk of bias; one because of the small number of participants and case finding (Brisbane night-club study), one because the population described was recruited in a Lesbian, Gay, Bisexual, Trans (LGBT) clinic but it was not clearly stated as purely MSM (SPARK project) and one because the outcome reported was chlamydia/gonorrhea test positivity and not prevalence (Washington cohort). The problem with using chlamydia/gonorrhea test positivity is that the number of tests is used to calculate the outcome rather than the number of participants. The number of tests can be influenced by multisite testing or by repeated testing in certain individuals. Regarding the population reported in the SPARK project, the prevalence could be underreported given that MSM could have a higher prevalence of chlamydia/gonorrhea than the rest of the LGBT community. Findings only from the low risk of bias studies, do not vary from the general set of selected studies. The quality assessment checklist is presented in supplementary material (SDC 3). 


\section{Discussion}

Out of the 12 studies included in our review we were able to statistically assess the change in prevalence in 10 of them. In three studies there was a significant increase in chlamydia prevalence, whereas for gonorrhea, the prevalence increased and decreased in two studies apiece. The increases in chlamydia/gonorrhea prevalence in the North London and Melbourne cohorts are difficult to interpret. Screening rates increased over the course of the studies in both cases and the studies took place in a period when the incidences of STIs including gonorrhea in MSM were increasing in both countries ${ }^{40 s, 42 s, 43 s}$. It is also difficult to place much weight on the decrease in rectal gonorrhea infections detected in the Los Angeles cohort due to the small number involved ( $\mathrm{n}=9,1$ and 1 , for the three visits, respectively, in a cohort of 212).

On balance we conclude that our review provides little evidence that screening for gonorrhea and chlamydia in MSM has an effect on the prevalence of these organisms. This conclusion of lack of evidence is commensurate with the USPSTF systematic review ${ }^{30}$. However, because none of the studies included had control groups, we cannot exclude the possibility that screening had an effect on prevalence and that prevalence would have been significantly higher in the absence of screening programs. Randomized controlled trials may thus reveal that screening for gonorrhea and chlamydia in MSM has a statistically significant effect on prevalence. The main other limitations of our review include the small number of studies, a sample size of less than 500 in 5 studies and the considerable heterogeneity in study type. The majority of included studies were conducted in high-income countries, which limits the generalizability of the findings. Almost half of the studies were open cohort studies and as a result, the study populations could change considerably over time. Although other PrEP studies such as PROUD ${ }^{29}$ and IPERGAY ${ }^{28}$ included chlamydia/gonorrhea screening, their 
published results were not detailed enough to meet our study inclusion criteria. Lastly, our review was limited solely to the effect of screening on prevalence and did not take into account study characteristics such as condom use, contact tracing and partner therapy, which could have had a confounding effect on our results.

One of the paradoxes of gonorrhea control is that whereas treatment of gonorrhea in core groups is essential for infection control, this strategy may result in the generation of antibiotic resistance ${ }^{6,19,20}$. Indeed, a modeling study that investigated different gonorrhea screening strategies found that the strategy that focused on the core group was the one which maximized the probability of the generation and dissemination of antibiotic resistant gonorrhea ${ }^{21}$. A basic principle of preventing the emergence of antibiotic resistance is antibiotic stewardship, a key component of which is restricting the use of antibiotics to cases where benefits clearly outweigh risks ${ }^{44 s, 45 s}$. It is possible that treating asymptomatic gonorrhea and chlamydia may have other benefits such as preventing the acquisition and lowering the transmission of HIV and a reduction in symptomatic disease. Although a large number of cohort studies have found previous STIs - particularly rectal gonorrhea or chlamydia infection - to be risk factors for HIV infection ${ }^{46 s-48 s}$, an article that summarized the efficacy of STI treatment on reducing HIV incidence in predominantly heterosexual populations found evidence for this effect in only one of 8 randomized controls trials ${ }^{49 s}$. No randomized controlled trials we are aware of have tested this effect in MSM populations. According to the WHO, two of the criteria for introducing screening programs are that there should be scientific evidence of screening effectiveness and that the overall benefits of screening should outweigh the harms ${ }^{50 s}$. The only benefit our study evaluated was a reduction in prevalence, which we were unable to confirm. While we note a number of limitations to our review it also needs to be borne in mind that the rates of screening for chlamydia/gonorrhea outside of trial settings are generally 
far lower than those reported in the studies we reviewed. The European MSM Internet Survey (EMIS), for example, surveyed over 180000 men in 38 European countries and asked the respondents if they had a genital and/or anal swab as part of STI screening in the past 12 months ${ }^{51 \mathrm{~s}}$. The median (interquartile range) country-level screening rates for these 38 countries was $15.9 \%(12.1-22.4 \%)$ for anal screening and $55.2 \%(45.6-70.2 \%)$ for genital screening. These represent upper limit estimates of coverage since they exclude pharyngeal and combined three-site screening. Even so they suggest that the prevalence of screening in MSM population settings is far lower than those in the studies we included. Furthermore, our review did not consider other possible adverse effects of screening programs such as interrupting the development of immunity to gonorrhea and chlamydia ${ }^{52 s, 53 s}$, and the falsesense of security that screening may produce ${ }^{54 \mathrm{~s}}$.

In our review, no evidence was found to support a dose effect; frequent screening does not seem to reduce prevalence more effectively than annual screening. However, among the selected studies, the frequency of screening overlaps almost completely with the type of the study, with open cohort having annual screening and closed population studies more frequent screening. Even 3 monthly screening in closed cohorts was not associated with a reduction in prevalence. This raises the possibility that the connectivity of sexual networks in these studies is so high that screening makes little difference to prevalence. Modeling studies may be useful to ascertain thresholds for screening efficacy on prevalence according to network characteristics ${ }^{45 \mathrm{~s}, 46 \mathrm{~s}, 55 \mathrm{~s}}$. A finding from a modeling study by Althaus et al., for example, demonstrated a coverage of $30 \%$ or more of the target population each year is needed to significantly reduce chlamydia prevalence ${ }^{45 s, 46 s}$. In their modeling study, Jenness et al., found that screening $40 \%$ of MSM for gonorrhea/chlamydia in a PrEP program would avert $42 \% / 40 \%$ of these infections over the next decade ${ }^{55 s}$. They do not however consider transmission between the oropharynx and other sites in their model. An arguably more 
realistic transmission model that included transmissions between the urethra, rectum and oropharynx found that current screening intensity was having little impact on the prevalence of gonorrhea in MSM in Belgium ${ }^{56 s}$.

In conclusion, if there is inadequate evidence of a benefit of screening for gonorrhea and chlamydia in MSM then the best way to generate this evidence would be to conduct cluster randomized controlled trials in high and low risk MSM groups. Outcomes of interest should ideally include effect on the prevalence of gonorrhea/chlamydia and HIV, the resistome and behavior. 


\section{ACKNOWLEDGEMENTS}

This work was in part supported by the FWO Scientific Research Community on Network Statistics for Sexually Transmitted Infections Epidemiology grant number W0.025.14N. NH gratefully acknowledges support from the University of Antwerp scientific chair in Evidence-Based Vaccinology, financed in 20092017 by a gift from Pfizer. 


\section{REFERENCES}

1. Low N, Unemo M, Skov Jensen J, Breuer J, Stephenson JM. Molecular Diagnostics for Gonorrhoea: Implications for Antimicrobial Resistance and the Threat of Untreatable Gonorrhoea. PLoS Med. 2014;11(2). doi:10.1371/journal.pmed.1001598.

2. Kirkcaldy RD, Harvey A, Papp JR, et al. Antimicrobial Susceptibility Surveillance — The Gonococcal Isolate Surveillance Project, 27 Sites, United States, 2014. MMWR Surveill Summ. 2016;65(7).

3. STD Prevention Conference [Press Release]. New Warning Signs that Gonorrhea Treatment May be Losing Effectiveness. In: ; 2016. http://www.cdc.gov/nchhstp/newsroom/2016/2016-std-preventionconference-press-release.html (Accessed: June 30 2017).

4. Blomquist P, Miari V, Biddulph J, Charalambous B. Is gonorrhea becoming untreatable? Futur Microbiol. 2014;9(2):189-201. doi:10.2217/fmb.13.155.

5. Ndowa F, Lusti-Narasimhan M, Unemo M. The serious threat of multidrug- resistant and untreatable gonorrhoea: the pressing need for global action to control the spread of antimicrobial resistance, and mitigate the impact on sexual and reproductive health. Sex Transm Infect. 2012;88(5):317-318. doi:10.1136/sextrans-2012-050674.

6. Lewis DA. The role of core groups in the emergence and dissemination of antimicrobial-resistant $\mathrm{N}$ gonorrhoeae. Sex Transm Infect. 2013;89(Suppl 4):iv47-iv51. doi:10.1136/sextrans-2013-051020.

7. Unemo M. Current and future antimicrobial treatment of gonorrhoea - the rapidly evolving Neisseria gonorrhoeae continues to challenge. BMC Infect Dis. 2015;15:364. doi:10.1186/s12879-015-1029-2.

8. Lewis DA. Will targeting oropharyngeal gonorrhoea delay the further emergence of drug-resistant Neisseria gonorrhoeae strains? Sex Transm Infect. 2015:sextrans-2014-051731-. doi:10.1136/sextrans-2014-051731.

9. Keaveney S, Sadlier C, O’Dea S, Delamere S, Bergin C. High prevalence of asymptomatic sexually transmitted infections in HIV-infected men who have sex with men: a stimulus to improve screening. Int J STD AIDS. 2014;25(10):758-761. doi:10.1177/0956462414521165.

10. European Centre for Disease Prevention and Control. HIV and STI Prevention among Men Who Have Sex with Men. Stockholm: ECDC; 2015. doi:10.2900/66666. 
11. Workowski K, Bolan G. Sexually Transmitted Diseases Treatment Guidelines. MMWR Recomm Rep. 2015;64(RR3):1-137. doi:10.1097/00008480-200308000-00006.

12. Asboe D, Aitken C, Boffito M, et al. British HIV Association guidelines for the routine investigation and monitoring of adult HIV-1-infected individuals 2011. HIV Med. 2012;13(1):1-44. doi:10.1111/j.1468-1293.2011.00971.x.

13. Sexually Transmissible Infections in Gay Men Action Group (STIGMA). Australian Sexually Transmitted Infection \& HIV Testing Guidelines 2014 for Asymptomatic Men Who Have Sex with Men.; 2014. http://stipu.nsw.gov.au/wp-content/uploads/STIGMA_Testing_Guidelines_Final_v5.pdf.

14. World Health Organisation. Prevention and Treatment of HIV and Other Sexually Transmitted Infections among Men Who Have Sex with Men and Transgender People. Recommendations for a Public Health Approach 2011. http://apps.who.int/iris/bitstream/10665/44619/1/9789241501750_eng.pdf.

15. LeFevre ML. Screening for chlamydia and gonorrhea: U.S. Preventive Services Task Force recommendation statement. Ann Intern Med. 2014;161(12):902-910. doi:10.7326/M14-1981.

16. Templeton DJ, Read P, Varma R, Bourne C. Australian sexually transmissible infection and HIV testing guidelines for asymptomatic men who have sex with men 2014: A review of the evidence. Sex Health. 2014;11(3):217-229. doi:10.1071/SH14003.

17. Public Health Agency of Canada. Canadian Guidelines on Sexually Transmitted Infections. Ottawa, ON; 2010. doi:10.1007/s13398-014-0173-7.2.

18. Xiridou M, Vriend HJ, Lugner AK, et al. Modelling the impact of chlamydia screening on the transmission of HIV among men who have sex with men. BMC Infect Dis. 2013;13(436)(1):1-10. doi:10.1186/1471-2334-13-436.

19. Laxminarayan R, Duse A, Wattal C, et al. Antibiotic resistance-the need for global solutions. Lancet Infect Dis. 2013;13(12):1057-1098. doi:10.1016/S1473-3099(13)70318-9.

20. Fingerhuth SM, Bonhoeffer S, Low N, Althaus CL. Antibiotic-Resistant Neisseria gonorrhoeae Spread Faster with More Treatment, Not More Sexual Partners. PLoS Pathog. 2016;12(5):1-15. doi:10.1371/journal.ppat.1005611.

21. Chan $\mathrm{CH}, \mathrm{McCabe} \mathrm{CJ}$, Fisman DN. Core groups, antimicrobial resistance and rebound in gonorrhoea 
in North America. Sex Transm Infect. 2012;88(3):200-204. doi:10.1136/sextrans-2011-050049.

22. Liu AY, Cohen SE, Vittinghoff E, et al. Preexposure Prophylaxis for HIV Infection Integrated With Municipal- and Community-Based Sexual Health Services. JAMA Intern Med. 2016;176(1):75-84. doi:10.1001/jamainternmed.2015.4683.

23. Grant RM, Lama JR, Anderson PL, et al. Preexposure Chemoprophylaxis for HIV Prevention in Men Who Have Sex with Men. N Engl J Med. 2010;363:2587-2599.

24. Morris SR, Klausner JD, Buchbinder SP, et al. Prevalence and incidence of pharyngeal gonorrhea in a longitudinal sample of men who have sex with men: the EXPLORE study. Clin Infect Dis. 2006;43(10):1284-1289. doi:10.1086/508460.

25. Brook G, Mcsorley J, Shaw a. Retrospective study of the effect of enhanced systematic sexually transmitted infection screening, facilitated by the use of electronic patient records, in an HIV-infected cohort. HIV Med. 2013;14(6):347-353. doi:10.1111/hiv.12020.

26. Golub SA, Peña S, Boonrai K, Douglas N, Hunt M, Radix A. STI Data from Community-Based PrEP Implementation Suggest Changes to CDC Guidelines. New York, NY, US; 2015.

27. Kenyon CR, Osbak K, Vandenbruane M. What is the appropriate therapy for asymptomatic gonorrhoea in men who have sex with men? Int $J$ STD AIDS. 2016;27(9):812-813. doi:10.1177/0956462416642933.

28. Gall J Le, Cua E, Pasquet A, et al. On-Demand Preexposure Prophylaxis in Men at High Risk for HIV-1 Infection. N Engl J Med. 2015;373:2197-2199. doi:10.1056/NEJMoa1506273.

29. McCormack S, Dunn DT, Desai M, et al. Pre-exposure prophylaxis to prevent the acquisition of HIV1 infection (PROUD): Effectiveness results from the pilot phase of a pragmatic open-label randomised trial. Lancet. 2016;387(10013):53-60. doi:10.1016/S0140-6736(15)00056-2.

30. Zakher B, Cantor AG, Pappas M, Daeges M, Nelson HD. Screening for gonorrhea and chlamydia: A systematic review for the U.S. Preventive Services Task Force. Ann Intern Med. 2014;161(12):884893. doi:10.7326/M14-1022. 
Caption for Figure 1: Flow diagram of study inclusion

Caption for figure 2a: Chlamydia trachomatis prevalence change between baseline and 6 months by study and anatomical sampling site

Caption for figure 2b: Chlamydia trachomatis prevalence change between baseline and 12 months by study and anatomical sampling site

Caption for figure 3a: Neisseria gonorrhoeae prevalence change between baseline and 6 months by study and anatomical sampling site

Caption for figure 3b: Neisseria gonorrhoeae prevalence change between baseline and 12 months by study and anatomical sampling site

Caption for figure 4: Aggregated Chlamydia trachomatis and Neisseria gonorrhoeae prevalence by study and anatomical sampling site 


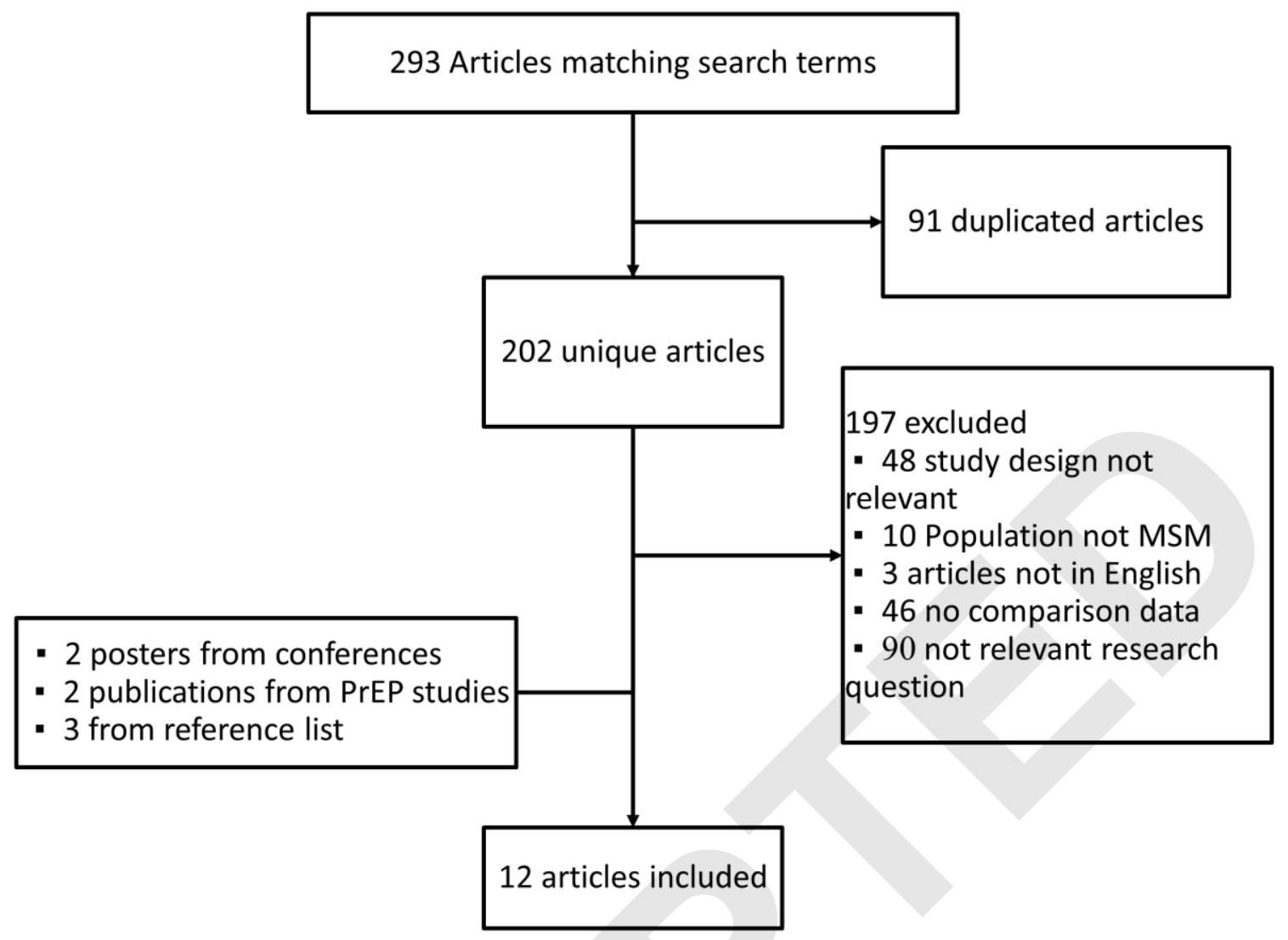




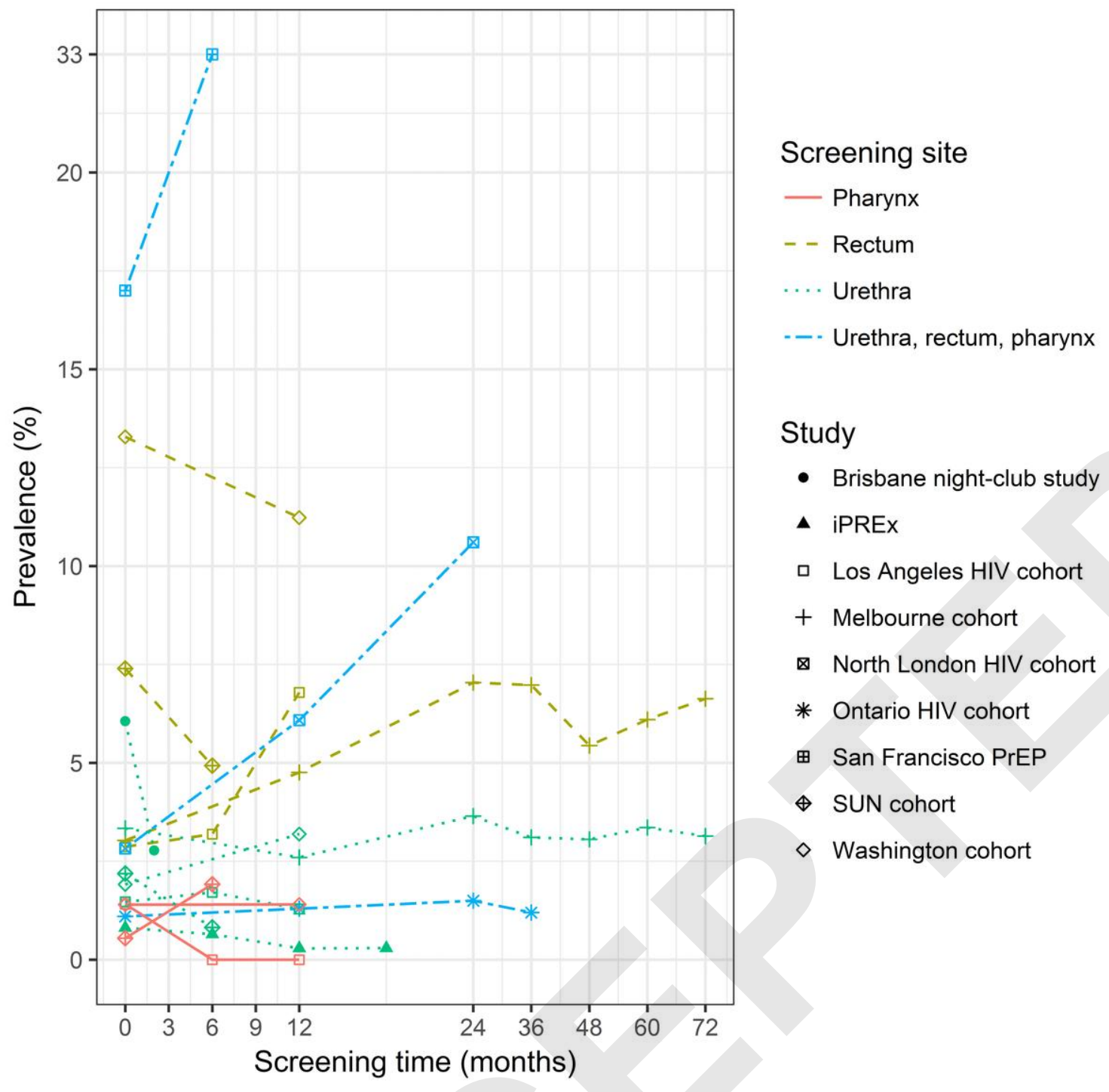


Study

SPARK

SPARK

iPREx

Demo PrEP project

Demo PrEP project

Demo PrEP project

SUN cohort

SUN cohort

SUN cohort

Los Angeles HIV cohort

Los Angeles HIV cohort

Los Angeles HIV cohort
Anatomical site

Rectum (NG and CT together)

Urethra (NG and CT together)

Urethra

Pharynx (NG and CT together)

Rectum (NG and CT together)

Urethra (NG and CT together)

Pharynx

Rectum

Urethra

Pharynx

Rectum

Urethra

$\begin{array}{lllll}-0.125 & -0.05 & 0 & 0.05 & 0.1\end{array}$

Chlamydia prevalence change between basel 
ihlamydia prevalence change between baseline and 12 month

Study

Washington cohort

Washington cohort

Washington cohort

North London HIV cohort

Melbourne cohort

Melbourne cohort

SPARK

SPARK

iPREx

Demo PrEP project

Demo PrEP project

Demo PrEP project

Los Angeles HIV cohort

Los Angeles HIV cohort

Los Angeles HIV cohort
Anatomical site

Pharynx

Rectum

Urethra

Urethra, rectum, pharynx

Rectum

Urethra

Rectum (NG and CT together)

Urethra (NG and CT together)

Urethra

Pharynx (NG and CT together)

Rectum (NG and CT together)

Urethra (NG and CT together)

Pharynx

Rectum

Urethra

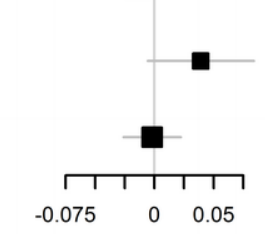




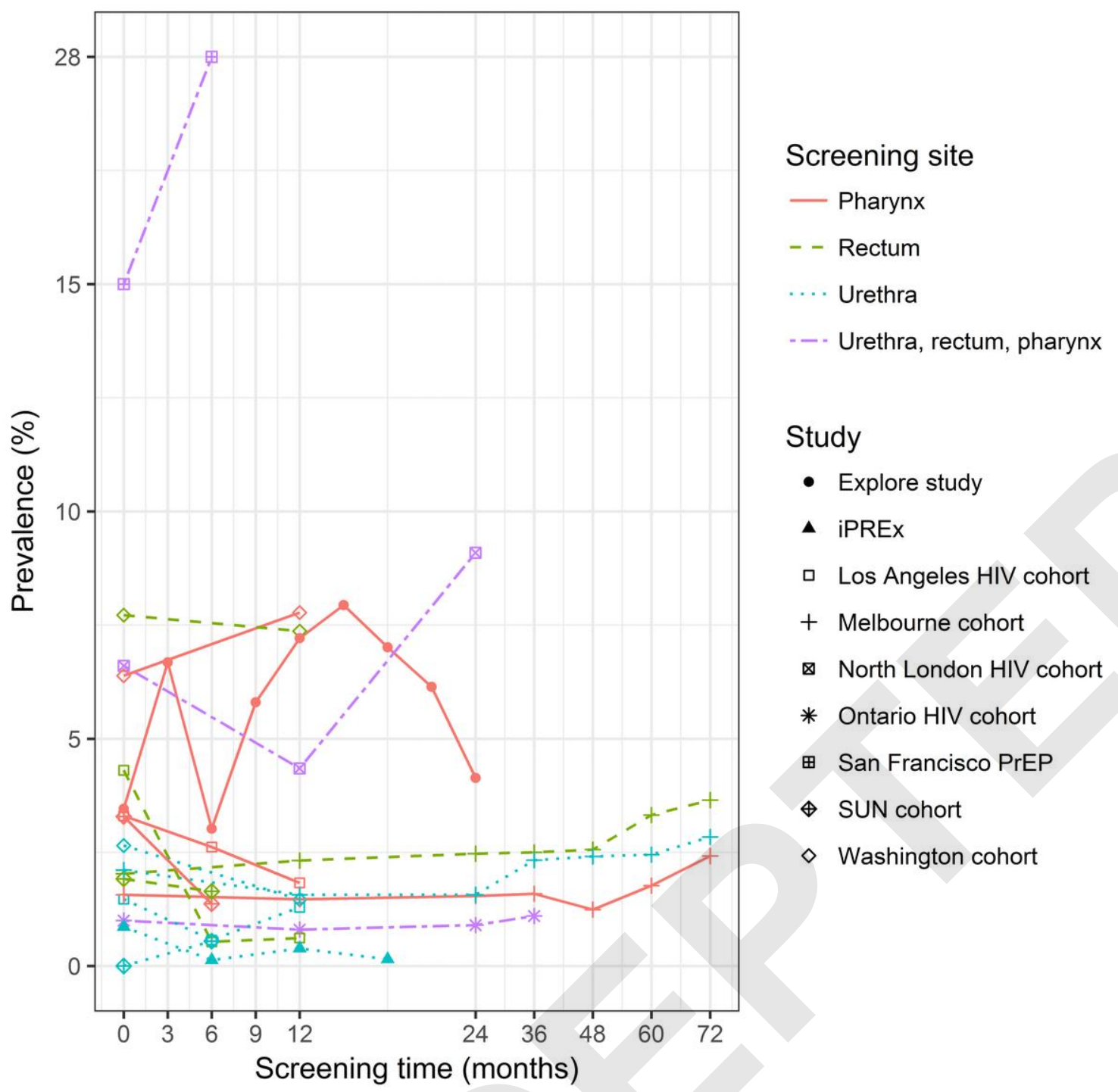


Study

SPARK

SPARK

iPREx

Demo PrEP project

Demo PrEP project

Demo PrEP project

SUN cohort

SUN cohort

SUN cohort

Los Angeles HIV cohort

Los Angeles HIV cohort

Los Angeles HIV cohort
Anatomical site

Rectum (NG and CT together)

Urethra (NG and CT together)

Urethra

Pharynx (NG and CT together)

Rectum (NG and CT together)

Urethra (NG and CT together)

Pharynx

Rectum

Urethra

Pharynx

Rectum

Urethra

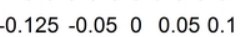

Gonorrhea prevalence change between base 
ionorrhea prevalence change between baseline and 12 month

Study

Washington cohort

Washington cohort

Washington cohort

North London HIV cohort

Melbourne cohort

Melbourne cohort

SPARK

SPARK

iPREx

Demo PrEP project

Demo PrEP project

Demo PrEP project

Los Angeles HIV cohort

Los Angeles HIV cohort

Los Angeles HIV cohort
Anatomical site

Pharynx

Rectum

Urethra

Urethra, rectum, pharynx

Rectum

Urethra

Rectum (NG and CT together)

Urethra (NG and CT together)

Urethra

Pharynx (NG and CT together)

Rectum (NG and CT together)

Urethra (NG and CT together)

Pharynx

Rectum

Urethra 


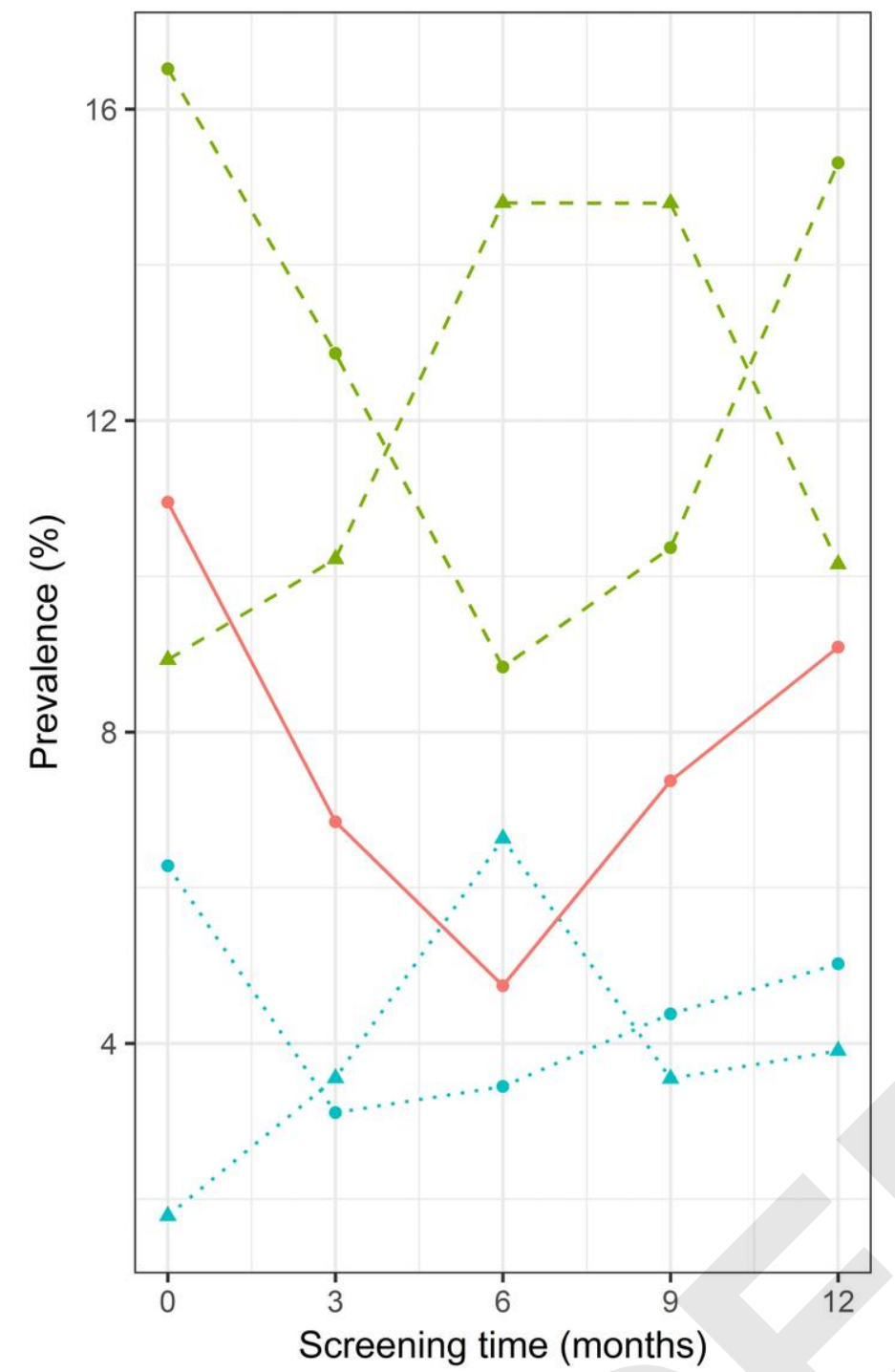

Study

- Demo PrEP project

- SPARK

\section{Screening site}

- Pharynx (NG and CT together)

- - Rectum (NG and CT together)

.... Urethra (NG and CT together) 
Table 1: A non-exhaustive selection of MSM STI screening guidelines

\begin{tabular}{|l|l|l|}
\hline \hline & Frequency & Sites \\
\hline $\begin{array}{l}\text { Centers for Disease Control and Prevention } \\
(\mathrm{CDC})^{11}\end{array}$ & $\begin{array}{l}\text { At least annually (every 3-6 months if at } \\
\text { increased risk) }\end{array}$ & $\begin{array}{l}\text { urethra, rectum, pharynx regardless of } \\
\text { condom use }\end{array}$ \\
\hline $\begin{array}{l}\text { European Centre for Disease Prevention and } \\
\text { Control (ECDC) }\end{array}$ & No recommendation & rectum, penis, urethra, pharynx \\
\hline British HIV association ${ }^{12}$ & $\begin{array}{l}\text { At least annually (more frequently if at increased } \\
\text { risk) }\end{array}$ & Not mentioned \\
\hline WHO $^{14}$ & $\begin{array}{l}\text { Conditional recommendation, low quality of } \\
\text { evidence }\end{array}$ & rectum, urethra \\
\hline${\text { US Preventive Services Task Force }{ }^{15}}_{\text {The USPSTF concludes that the current evidence }}$ & $\begin{array}{l}\text { is insufficient to assess the balance of benefits } \\
\text { and harms of screening for chlamydia and } \\
\text { gonorrhea in men. }\end{array}$ & recturethra, pharynx \\
\hline Australian MSM Screening Guidelines ${ }^{13,16}$ & $\begin{array}{l}\text { At least annually (up to 3 monthly if at increased } \\
\text { risk) }\end{array}$ & rectum, urethra, pharynx \\
\hline Public Health Agency of Canada ${ }^{17}$ & At least annually & all potential sites of infection \\
\hline
\end{tabular}


Caption for Table 2: Study design and characteristics of the 12 studies included in the systematic review

\begin{tabular}{|c|c|c|c|c|c|c|c|c|c|c|c|}
\hline & Author & Study & Study design & $\begin{array}{l}\text { Sample } \\
\text { size }\end{array}$ & Population & Year & $\begin{array}{l}\text { Screening } \\
\text { frequency }\end{array}$ & $\begin{array}{l}\text { Screening/ } \\
\text { retention } \\
\text { rateđI }\end{array}$ & $\begin{array}{c}\text { Diagnosis } \\
\text { method }\end{array}$ & STI & Screening site \\
\hline \multirow{5}{*}{$\begin{array}{c}\text { Open } \\
\text { population } \\
\text { studies }\end{array}$} & Barbee et al & Washington cohort & $\begin{array}{l}\text { Repeated cross- } \\
\text { sectional survey }\end{array}$ & 1520 & $\begin{array}{l}\text { MSM (HIV } \\
\text { status not } \\
\text { reported) }\end{array}$ & $2012-2014$ & Annually & $16-31 \%$ & NAAT & $\mathrm{NG}, \mathrm{CT}$ & $\begin{array}{l}\text { Pharynx, Rectum, } \\
\text { Urethra }\end{array}$ \\
\hline & Brook et al & $\begin{array}{l}\text { North London HIV } \\
\text { cohort }\end{array}$ & Retrospective cohort & 132 & $\mathrm{HIV}^{+} \mathrm{MSM}$ & Aug 2009 - Jul 2012 & Annually & $90-97 \%$ & $\begin{array}{c}\text { Not } \\
\text { mentioned }\end{array}$ & $\mathrm{NG}, \mathrm{CT}$ & $\begin{array}{l}\text { Pharynx, Rectum, } \\
\text { Urethra } \\
\text { (aggregated) }\end{array}$ \\
\hline & Burchell et al & Ontario HIV cohort & $\begin{array}{l}\text { Repeated cross- } \\
\text { sectional survey }\end{array}$ & 2179 & $\mathrm{HIV}^{+} \mathrm{MSM}$ & $2008-2011$ & Annually & $39 \%$ & $\begin{array}{l}\text { NAAT \& } \\
\text { culture }\end{array}$ & $\mathrm{NG}, \mathrm{CT}$ & $\begin{array}{l}\text { Pharynx, Rectum, } \\
\text { Urethra } \\
\text { (aggregated) }\end{array}$ \\
\hline & Chow et al & Melbourne cohort & Retrospective cohort & 12873 & $\begin{array}{l}\text { MSM (HIV } \\
\text { status not } \\
\text { reported) }\end{array}$ & Jan 2007 - Dec 2013 & Annually & $75-93 \%$ & NAAT & $\mathrm{NG}, \mathrm{CT}$ & $\begin{array}{l}\text { Pharynx, Rectum, } \\
\text { Urethra }\end{array}$ \\
\hline & Debattista et al & $\begin{array}{l}\text { Brisbane night-club } \\
\text { study }\end{array}$ & $\begin{array}{l}\text { Repeated cross- } \\
\text { sectional survey }\end{array}$ & 184 & $\begin{array}{l}\text { MSM (HIV } \\
\text { status not } \\
\text { reported) }\end{array}$ & Mar 2000 - Jul 2000 & $\begin{array}{l}\text { Baseline and } \\
\text { month } 2\end{array}$ & $40 \%$ & $\begin{array}{l}\text { NAAT \& } \\
\text { culture }\end{array}$ & $\mathrm{NG}, \mathrm{CT}$ & Pharynx, Urethra \\
\hline \multirow{7}{*}{$\begin{array}{l}\text { Closed } \\
\text { population } \\
\text { studies }\end{array}$} & Golub et al & $\begin{array}{l}\text { Community based } \\
\text { PREP (SPARK) }\end{array}$ & Prospective cohort & 280 & & & Every 3 months & $54 \%$ & $\begin{array}{c}\text { Not } \\
\text { mentioned }\end{array}$ & $\begin{array}{c}\text { NG, CT } \\
\text { (aggregated) }\end{array}$ & Rectum, Urethra \\
\hline & Grant et al & iPREx & $\begin{array}{l}\text { RCT for PrEP } \\
\text { effectiveness }\end{array}$ & 2451 & $\begin{array}{c}\mathrm{HIV}^{-} \\
\text {MSM/TGW }\end{array}$ & Jul 2007 - Dec 2009 & Every 6 months & $72 \%$ & NAAT & $\mathrm{NG}, \mathrm{CT}$ & Urethra \\
\hline & Liu et al & Demo PrEP project & Prospective cohort & 557 & $\begin{array}{c}\mathrm{HIV}^{-} \\
\text {MSM/TGW }\end{array}$ & Oct 2012 - Jan 2014 & Every 3 months & $75 \%$ & NAAT & $\begin{array}{c}\text { NG, CT } \\
\text { (aggregated) }\end{array}$ & $\begin{array}{l}\text { Pharynx, Rectum, } \\
\text { Urethra }\end{array}$ \\
\hline & Mayer et al & SUN cohort & Prospective cohort & 365 & $\mathrm{HIV}^{+} \mathrm{MSM}$ & Mar 2004 - Jun 2006 & Every 6 months & Not reported & NAAT & $\mathrm{NG}, \mathrm{CT}$ & $\begin{array}{l}\text { Pharynx, Rectum, } \\
\text { Urethra }\end{array}$ \\
\hline & Morris et al & Explore study & $\begin{array}{l}\text { RCT of behavioral } \\
\text { intervention }\end{array}$ & 603 & $\mathrm{HIV}^{-} \mathrm{MSM}$ & Mar 2001 - Jul 2003 & Every 3 months & Not reported & NAAT & NG only & Pharynx \\
\hline & Rieg et al & $\begin{array}{l}\text { Los Angeles HIV } \\
\text { cohort }\end{array}$ & Prospective cohort & 212 & $\mathrm{HIV}^{+} \mathrm{MSM}$ & Apr 2004 - Sep 2006 & Every 6 months & $79 \%$ & NAAT & $\mathrm{NG}, \mathrm{CT}$ & $\begin{array}{l}\text { Pharynx, Rectum, } \\
\text { Urethra }\end{array}$ \\
\hline & Volk et all & San Francisco PrEP & Prospective cohort & 653 & $\mathrm{HIV}^{-} \mathrm{MSM}$ & Jul 2012 - Feb 2015 & Every 6 months & Not reported & NAAT & $\mathrm{NG}, \mathrm{CT}$ & $\begin{array}{l}\text { Pharynx, Rectum, } \\
\text { Urethra } \\
\text { (aggregated) }\end{array}$ \\
\hline
\end{tabular}

II: Screening rate (coverage) is reported for open population studies and retention rates for closed population studies.

MSM: Men who have sex with men

TGW: Trans-gender women

NAAT: Nucleic Acid Amplification Test

CT: Chlamydia Trachomatis

NG: Neisseria Gonorrhoeae 
Table 3: Screening data and test results of the included studies.

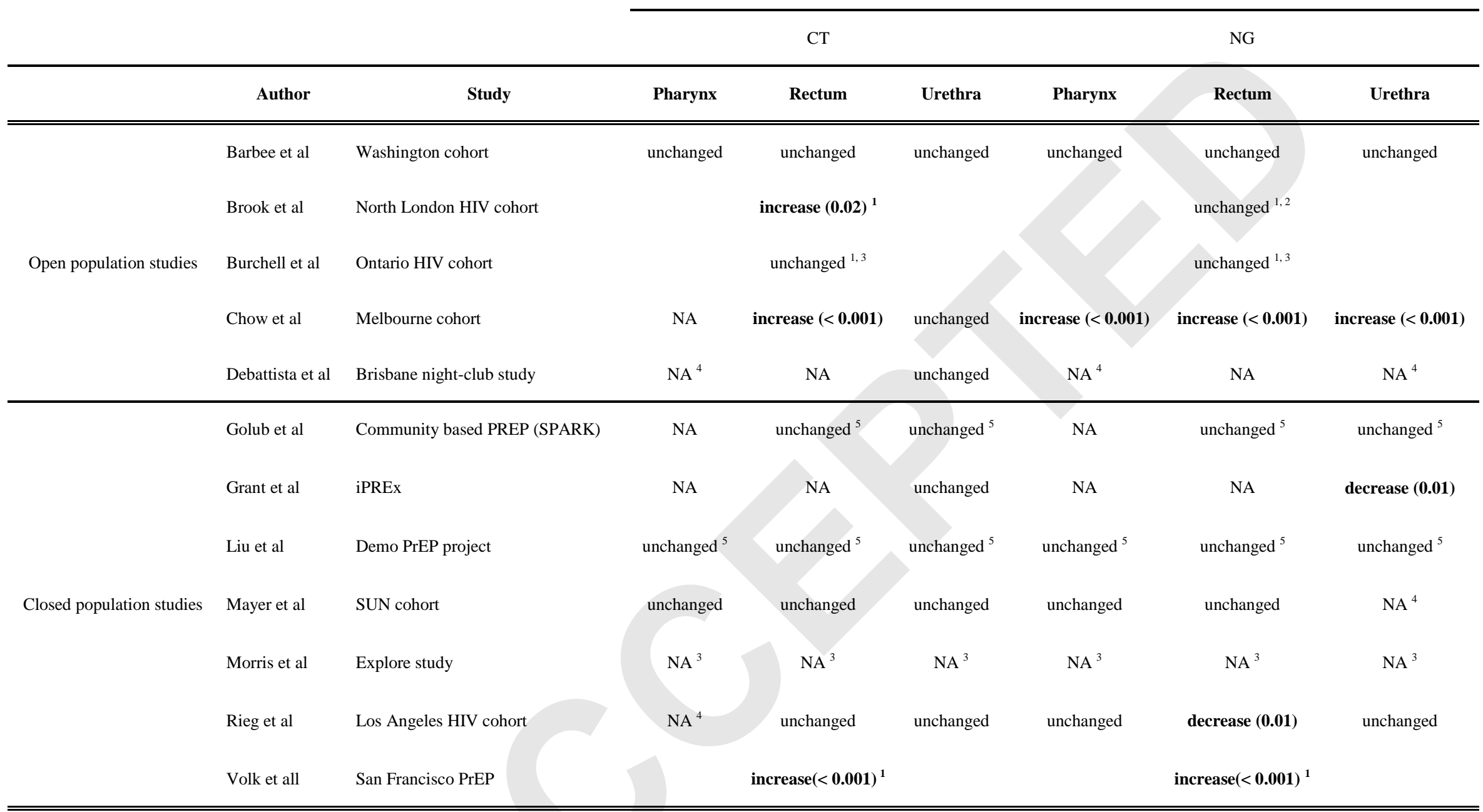

NA: Not applicable, numbers in parentheses are p-values from the Chi-square test for trend in proportions

${ }^{1}:$ Aggregated for pharynx, rectum and urethra

2 : Significant rise was reported in the paper between the second and the third year

: Number of tested was not reported

$4:$ Not applicable due to no reported cases

${ }^{5}$ : Aggregated for CT and NG 